\title{
The Prevalence of Cancer and its Associated Risk Factors among Patients Visiting Oncology Unit, Tikur Anbessa Specialized Hospital, Addis Ababa- Ethiopia
}

Minyahil Alebachew Woldu ${ }^{*}$, Dejenu Aklilu Legese ${ }^{\dagger}$, Faysel Ebrahim Abamecha ${ }^{\dagger}$ and Alemseged Beyene Berha ${ }^{\dagger}$

Department of Pharmacology and Clinical Pharmacy, School of Pharmacy, College of Health Sciences, Addis Ababa University, Addis Ababa, Ethiopia ${ }^{\dagger}$ Equal contributors

\begin{abstract}
Background: The global burden of cancer continues to increase largely because of the aging and growth of the world population alongside an increasing adoption of cancer-causing behaviors, particularly smoking, in economically developing countries. Cancer (CA) is an increasing public health burden for Ethiopia and SubSaharan Africa at large. In Ethiopia, hospital records show that there are more than 150,000 cancer cases per year and currently cancer accounts for $4 \%$ of all deaths.
\end{abstract}

Objective: The present prospective cross-sectional study was designed to assess the prevalence of cancer and its associated risk factors in patients visiting Tikur Anbessa Specialized Hospital (TASH).

Methods: A prospective cross-sectional study was carried out in patients of all age groups visiting oncology unit of TASH during the study period of November 2015 to June 2016. Sample size was computed using margin of error $5 \%$, confidence level of $95 \%$ and estimating cancer patients visiting TASH per annum equal to 20000 . The response distribution was taken 10\%, considering the 2012 Cancer Prevalence Report of the WHO in East Africa $5 \%$ to $10 \%$. The calculated sample size then was 142 .

Result and discussion: The mean age of the participants in our study was 42.27 year with a standard deviation of 16.8 , and 2 and 86 years were the age range. More than half of the patients in the study $(61.3 \%, n=87)$ were females and about $(38.7 \%, n=55)$ were males. In the study area uterine, breast, cervical, colorectal and gastric CA were more prevalent in the age group between 25-49 years while Acute Lymphoblastic Leukemia (ALL) was more common in 13-18 years of age, Ewing sarcoma was seen in age between 19 and 24 years. In our findings, breast CA $(14.8 \%, n=21)$ was the most frequent type of CA followed by uterine CA $(14.1 \%, n=20)$, colorectal CA $(11.3 \%$, $n=16)$, gastric cancer CA $(7.7 \%, n=11)$, cervical and esophageal cancers $(7 \%, n=10)$. ALL was commonly seen in students, while gastric, lung, AML, osteosarcoma; and squamous cell CA were common in farmers. Furthermore, among 20 patients who had breast CA, $65 \%(n=13)$ were used contraceptives at least once in their last 10 years period, while uterine cancer patients $(40 \%, n=8)$ were used either oral or injectable contraceptives. The prevalence of breast CA was not affected by the duration of contraceptive use rather it was stable across the duration of use. Many patients who were developed colorectal CA $12(8.5 \%)$ and gastric CA $9(6.3 \%)$ were reported that they were regularly consuming uncooked red meat as their favorite meal. In our study, many patients were receiving radiation therapy for cases such as uterine, breast, cervical and colorectal CA while chemotherapy was predominantly used in cases such as colorectal, squamous cell, osteosarcoma, ALL, AML and lung cancer. The multinomial regression analysis result further revealed that there was a significant association between breast CA with age (25-49 year, P. value 0.016 ), Uterine and Cervical CA with gender (female, P. value 0.001 ); and eating of uncooked red raw meat with colorectal CA (P. value 0.011$)$

Conclusion: Cancer prevalence in the study area looks greatly jeopardizing the life of many Ethiopians in association with life styles. Hence, further studies should be done. Awareness creation programs to the people, allocation of public health preventive medicine approaches and in-depth governmental involvement in the area are highly needed.

Keywords: Cancer; Cancer associated risk factors; Oncology unit of Tikur Anbessa specialized hospital; TASH

\footnotetext{
Abbreviations: AAU: Addis Ababa University; AIDS: Acquired Immunodeficiency Syndrome; ALL: Acute Lymphoblastic Leukemia; AML: Acute Myeloid Leukemia; CA: Cancer; CHS: College of Health Sciences; CML: Chronic Myeloid Leukemia; CRC: Colorectal Cancer; DNA: Deoxyribonucleic Acid; ECA: Ethiopian Cancer Association; ESCC: Esophageal Squamous Cell Carcinoma; ETB: Ethiopian Birr; FAP: Familial Adenomatous Polyposis; GBD: Global Burden of Disease; GERD: Gastroesophageal Reflux Disease; HL: Hodgkin-Lymphoma; NHL: Non-Hodgkin Lymphoma; HPV: Human Papilloma Virus; SNNP: South Nation Nationalities and People Region; SOP: School of Pharmacy; SPSS: Statistical Package for Social Sciences; USA: United States of America; WHO: World Health Organization
}

\section{Introduction}

Cancer is a disease in which abnormal cells grow and reproduce

*Corresponding author: Minyahil Alebachew Woldu, Addis Ababa University, College of Health Sciences, School of Pharmacy, Department of Pharmacology and Clinical Pharmacy, P.O. Box 9086, Addis Ababa, Ethiopia, Tel: +251912648527; E-mail: minwoldu@gmail.com

Received April 12, 2017; Accepted April 22, 2017; Published April 24, 2017

Citation: Woldu MA, Legese DA, Abamecha FE, Berha AB (2017) The Prevalence of Cancer and its Associated Risk Factors among Patients Visiting Oncology Unit, Tikur Anbessa Specialized Hospital, Addis AbabaEthiopia. J Cancer Sci Ther 9: 414-421. doi: 10.4172/1948-5956.1000452

Copyright: ( 2017 Woldu MA, et al. This is an open-access article distributed under the terms of the Creative Commons Attribution License, which permits unrestricted use, distribution, and reproduction in any medium, provided the original author and source are credited. 
uncontrollably and invade nearby tissues by spreading to other parts of the body through blood streams and lymphatic systems hindering the activities of the normal cells [1,2]. The global burden of cancer continues to increase largely because of the aging and growth of the world population alongside an increasing adoption of cancer-causing behaviors, particularly smoking, in economically developing countries [3].

Cancer fall into two categories: Solid and hematological cancers. Solid tumor is an abnormal mass of tissue that usually does not contain cysts or liquid areas. Different types of solid tumors are named for the type of cells that form them. Examples of solid tumors are sarcomas, carcinomas, and lymphomas. Hematologic malignancies are forms of cancer that begin in the cells of blood-forming tissue, such as the bone marrow, or in the cells of the immune system. Examples of hematologic cancer are acute and chronic leukemia [4-6].

The exact causes of cancer are not known and very often no single cause can be found. Findings so far show that cancer causes are related to changes on genes. Such changes on genes are related to living habit such as tobacco smoking, unhealthy diet and physical inactivity, and environmental factors like exposure to infections and carcinogens, and longer life expectancy [7-9].

The burden of cancer is increasing in economically developing countries as a result of population aging and growth as well as, increasingly, an adoption of cancer-associated lifestyle choices including smoking, physical inactivity, and "westernized" diets. Regardless of all this, Cancer has received low priority for health care services in SubSaharan Africa [10-12].

Cancer arises through a series of somatic alterations in DNA that result in unrestrained cellular proliferation. Most of these alterations involve actual sequence changes in DNA (i.e. mutations). They may originate as a consequence of random replication errors, exposure to carcinogens (e.g. radiation), or faulty DNA repair processes. While most cancers arise sporadically, familial clustering of cancers occurs in certain families that carry a germline mutation in a cancer gene [13-15].

There are two major types of cancer genes. The first type comprises genes that positively influence tumor formation and are known as oncogenes. The second type of cancer genes negatively impact tumor growth and have been named tumor-suppressor genes. Both oncogenes and tumor-suppressor genes exert their effects on tumor growth through their ability to control cell division (cell birth) or cell death (apoptosis), although the mechanisms can be extremely complex [16-19].

Worldwide, about 25 million people are living with cancer. Each year, 7 million people die from it and 11 million new cases are diagnosed globally. In fact more people die from cancer than from AIDS, malaria and tuberculosis put together where $12.5 \%$ of all deaths each year in the world are due to cancer. The bad news is that the incidences of cancer in developing countries like Ethiopia,which are not prepared to control, is rising at an alarming rate where as it is declining in the developed world because they started timely to avert it $[20,21]$.

The World Health Organization (WHO) estimated in 2011 that 34\% of Ethiopian population is dying from non-communicable diseases, with a national cardiovascular disease prevalence of $15 \%$, cancer and chronic obstructive pulmonary disease prevalence of $4 \%$ each, and diabetes mellitus prevalence of $2 \%$ [22,23]. The resulting double burden of non-communicable diseases, with higher prevalence of preexisting communicable, maternal, perinatal and nutritional conditions, constrains the already-meagre health resources and hinders economic development in Ethiopia [16,24,25].

Similarly, global burden of disease (GBD) studies estimated agestandardized death rates of 800 per 100,000 populations for noncommunicable diseases in Ethiopia, of which higher death rates (approximately 450 per 100,000) were attributed to cardiovascular disease and diabetes, 150 per100,000 attributed to cancer, and 100 per 100,000 to chronic obstructive pulmonary disease $[25,26]$.

Cancer is an increasing public health burden for Ethiopia and SubSaharan Africa at large. In Ethiopia, hospital records show that there are more than 150,000 cancer cases per year and currently cancer accounts for $4 \%$ of all deaths. However, Cancer is the most neglected and least prioritized health issue in Ethiopia. On the other hand, the WHO report which updated on February 2015, shows Cancers figure is among the leading causes of morbidity and mortality worldwide, with approximately 14 million new cases and 8.2 million cancer related deaths in 2012, with 5.3 million deaths a year in low income countries. According to this report, the number of new cases is expected to rise by about $70 \%$ over the next 2 decades $[27,28]$. Hence, the present prospective cross-sectional study is designed to assess the prevalence of cancer and its associated risk factors in patients vesting Tikur Anbessa Specialized Hospital (TASH)-the only referral cancer center in Ethiopia until this time.

\section{Methodology}

\section{Study setting and period}

The study was carried out in oncology unit of TASH from November 2015 to June 2016. TASH is a referral and teaching hospital located in Arada sub city of Addis Ababa, Ethiopia. Until now, it has been the only site where cancer cases are treated within the country. The unit was giving services for the community with the workforce of four oncologists, three palliative care specialists, six pharmacists of which, three were working for adult age groups, two were for pediatrics and one of them who hold a master degree serves as manager, and there were 26 nurses working actively in the unit. This oncology unit was giving services with these workforces on both inpatient and outpatient basis. The inpatient ward has about 18 beds.

\section{Study design and study population}

A prospective cross-sectional study was carried out. Patients of all age groups visited oncology unit of TASH during the study period and those who were volunteer to participate in the study were the study population.

\section{Sample size determination and sampling method}

Sample size was computed using margin of error $5 \%$, confidence level of $95 \%$ and estimating cancer patients visiting TASH per annum equal to 20000. The response distribution was taken $10 \%$, considering the 2012 Cancer Prevalence Report of the WHO in East Africa 5\% to $10 \%$ [12]. The calculated sample size then was 142 . All patients willing to participate was included in the study.

\section{Inclusion and exclusion criteria}

Inclusion criteria: All Patients visiting oncology unit of TASH during study period. 
Exclusion criteria: Patients who were unwilling to participate were excluded.

\section{Study variables}

Dependent variable: Type of cancer

Independent variables: Risk factors

1) Socio-demographic factors such as age, sex, address, ethnicity, religion and marital status

2) Living habits such as source of drinking water, alcohol, exposure to carcinogens (occupation, contamination and accidents), diet, hormones, smoking, obesity, radiation, sunlight and immunosuppression.

\section{Data collection methods and tools}

Data was collected from November 2015 to June 2016 through reviewing the patients' medical records and interviewing either of patients, patients' parent or care giver. Structured questionnaires and checklists were used focusing on the assessment of risk factors. It contains three parts. The first part contains questions about the socio-demographic characteristics of the patients. The second part contains information about patient medical history and the third part contains questions related to living habits and risk factors associated with corresponding cancer types. The designed questionnaires were translated to local Amharic language and administered to willing study participants.

\section{Data management and analysis}

Daily collected data was checked for completeness and compiled and entered in to SPSS version 21. Tables, charts and graphs were used to present the result. Subgroup analysis was done to compare effects of independent variables using Chi-squared or Fishers exact test for categorical variables and Mann-Whitney tests for continuous variables. Logistic regression was done to assess the association of type of cancer with independent variables. A $95 \%$ CI and p-value of $<0.05$ was considered statistically significant.

\section{Ethical clearance}

Ethical clearance was obtained from Addis Ababa University, College of Health Science, School of Pharmacy Research and ethical review board (ERB) and supportive letter from Department of Pharmacology and Clinical Pharmacy was received to conduct the study. Permission was granted by the Head of TASH Oncology Department. 142 patients were interviewed using the structured questionnaire and their medical charts were reviewed after a verbal consent was secured.

\section{Quality assurance mechanisms}

Data collection was done by clinical pharmacy oriented bachelor of pharmacy final year students. Two students were given appropriate orientation on how to collect the data and interact with patients and other health care professionals. All steps in data collection and recording were closely supervised by the principal investigator. Daily taken data was scrutinized for accuracy, adequacy and consistency. Discussion among the research team was be done every week on the challenges, progress and success of the study.

\section{Result and Discussion}

A total of 142 patients were involved in the study. They were interviewed to identify the risk factors associated with corresponding cancer types and their medical charts were reviewed.

\section{Socio-demographic data}

Different studies have shown that, advancing age is the most potent of all carcinogens. In humans, the incidence of cancer rises exponentially in the final decades of life, culminating in a lifetime risk of 1 in 2 for men and 1 in 3 for women. This dramatic age-dependent escalation in cancer risk is fuelled largely by a marked increase in epithelial carcinomas from ages 40 to 80 years, as opposed to cancers of mesenchymal or haematopoietic origin [29]. Similarly, the mean age of the participants in our study was 42.27 years with a standard deviation of 16.75 years and 2 years and 86 years were the age range.

More than half of the patients in our study $(61.3 \%, \mathrm{n}=87)$ were females and about $(38.7 \%, \mathrm{n}=55)$ were males (Table 1 ). Most of the patients were from Addis Ababa $(32.4 \%, \mathrm{n}=46)$ and Oromia region $(31.7 \%, \mathrm{n}=45)$. This could be better explained by urbanization in case of Addis Ababa, and with respect of the Oromiya region population size could be the factor. The others were $(16.2 \%, n=23)$ from South Nation Nationalities and People Region (SNNP), (13.4\%, $n=19)$ from Amhara, $(4.2 \%, n=6)$ from Tigray and about $(2.1 \%, n=3)$ from others.

Of the patients, 59.9\% ( $\mathrm{n}=85)$ were Orthodox Christians, Muslims (22.5\%, $\mathrm{n}=32)$, Protestant Christians $(14.1 \%, \mathrm{n}=20)$, Adventists $(2.1 \%$, $\mathrm{n}=3)$ and Catholic Christians $(1.4 \%, \mathrm{n}=2)$. Of the study participants 66 $(46.5 \%)$ were illiterates, $(25.4 \%, \mathrm{n}=36)$ were attended primary school, $(19 \%, \mathrm{n}=27)$ were attended secondary school, $(5.6 \%, \mathrm{n}=8)$ were attended college while $(2.8 \%, \mathrm{n}=4)$ were attended University level (Table 1$)$.

\section{Cancer type by age distribution}

In our study uterine, breast, cervical, colorectal and gastric CA were more common in age group between 25-49 years while ALL was more common in 13-18 years of age, Ewing sarcoma was most prevalent in age between 19 and 24 years (Figure 1).

\section{Cancer type by sex distribution}

In our finding, breast CA $(14.8 \%, \mathrm{n}=21)$ was the most frequent type

\begin{tabular}{|c|c|c|}
\hline \multicolumn{2}{|c|}{ Socio-demographic characteristics } & \multirow{2}{*}{$\begin{array}{c}\text { Frequency (\%) } \\
55(38.7)\end{array}$} \\
\hline & Male & \\
\hline sex & Female & $87(61.3)$ \\
\hline \multirow{3}{*}{ Age } & $\leq 18$ year & $13(9.2)$ \\
\hline & $19-49$ & $83(58.5)$ \\
\hline & $\geq 50$ & $46(32.4)$ \\
\hline \multirow{4}{*}{ Educational status } & Illiterate & $66(46.5)$ \\
\hline & Primary & $36(25.4)$ \\
\hline & Secondary & $27(19)$ \\
\hline & Diploma and above & $12(8.45)$ \\
\hline \multirow{6}{*}{ Region } & Oromia & $45(31.7)$ \\
\hline & Amhara & $19(13.4)$ \\
\hline & SNNP & $23(16.2)$ \\
\hline & Tigray & $6(4.2)$ \\
\hline & Addis Ababa & $46(32.4)$ \\
\hline & Others & $3(2.1)$ \\
\hline \multirow{4}{*}{ Religion } & Orthodox, Christians & $85(59.9)$ \\
\hline & Muslim & $32(22.5)$ \\
\hline & Protestant, Christians & $20(14.1)$ \\
\hline & Others & $5(3.5)$ \\
\hline \multirow{3}{*}{ Marital status } & Single & $33(23.2)$ \\
\hline & Married & $107(75.4)$ \\
\hline & Others & $2(1.4)$ \\
\hline
\end{tabular}

Table 1: The Socio-demographic characteristics of the patients, Addis Ababa Ethiopia 2016 
of CA followed by uterine CA $(14.1 \%, \mathrm{n}=20)$, colorectal CA $(11.3 \%$, $\mathrm{n}=16)$, gastric cancer $\mathrm{CA}(7.7 \%, \mathrm{n}=11)$, cervical and esophageal cancers $(7 \%, \mathrm{n}=10)$. The result is in line with other findings across the globe $[30,31]$. For example, many studies reported that breast cancer was the most prevalent cancer in the vast majority of countries globally; and cervical cancer was the most prevalent cancer in much of Sub-Saharan Africa and Southern Asia while prostate cancer dominates in North America, Oceania and Northern and Western Europe [22,32].

Studies showed that cancer of the lung and bronchus, prostate, and colorectum was relatively common in men as compared to female where as cancers of the lung and bronchus, breast, and colorectum was common among female patients [33]. In our study female were commonly presented with breast CA $(22.98 \%, \mathrm{n}=20)$ and uterine cancer CA $(22.98 \%, n=20)$ while colorectal CA $(18.18 \%, n=10)$ and gastric cancer $(10.9 \%, \mathrm{n}=6)$ were common among male patients (Figure 2 ).

\section{Cancer type by occupation}

In our study, ALL was common in students, while gastric, lung, AML, osteosarcoma; and squamous cell CA were common in farmers (Figure 3). Other studies showed that rates of retinobiastoma, Wilms' tumor, non-Hodgkin's lymphoma, neuroblastoma, Hodgkin's disease, acute lymphoid leukemia, acute myeloid leukemia, and osteosarcoma

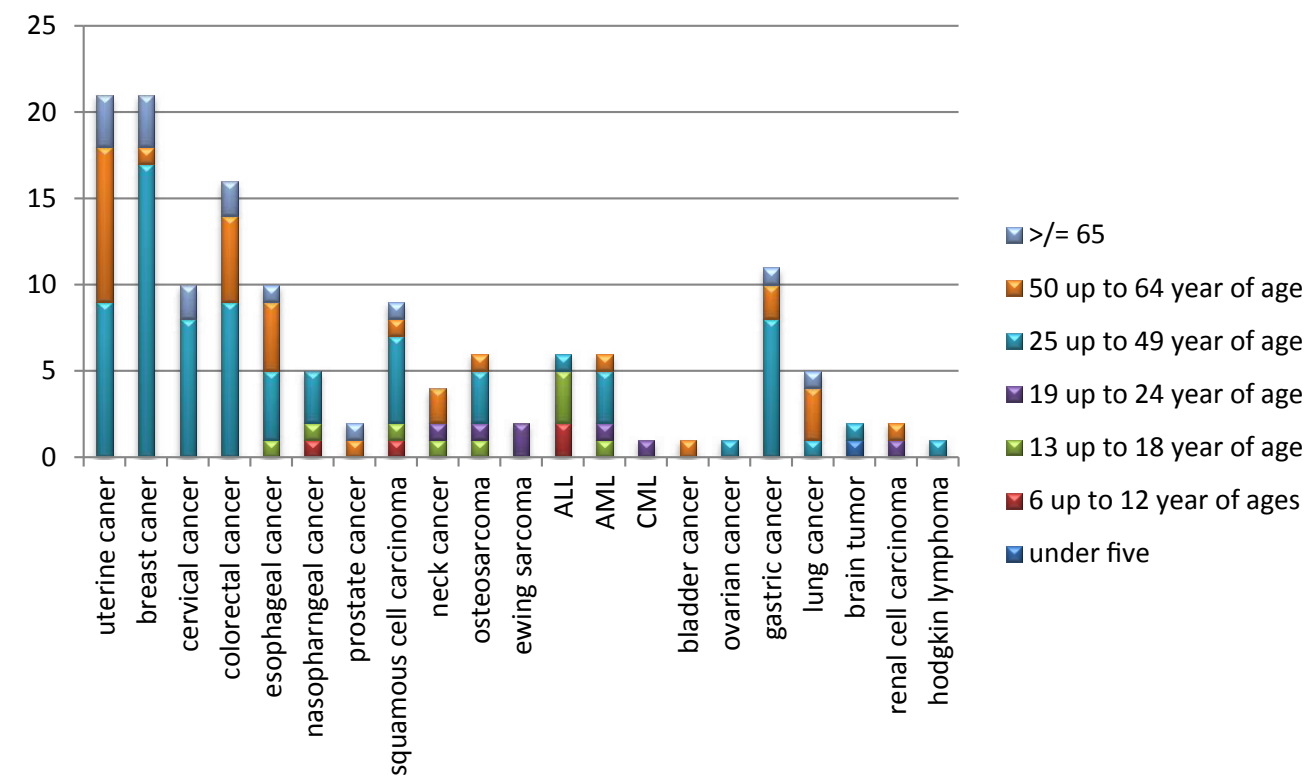

Figure 1: Patern of cancer type by age category at Onclolgy Unit of Tikur Anbessa Specilized Hospital, Addis Ababa, 2016.



Cancer Type

Figure 2: Patern of cancer type by sex at Onclolgy Unit of Tikur Anbessa Specilized hospital, Addis Ababa, 2016. 


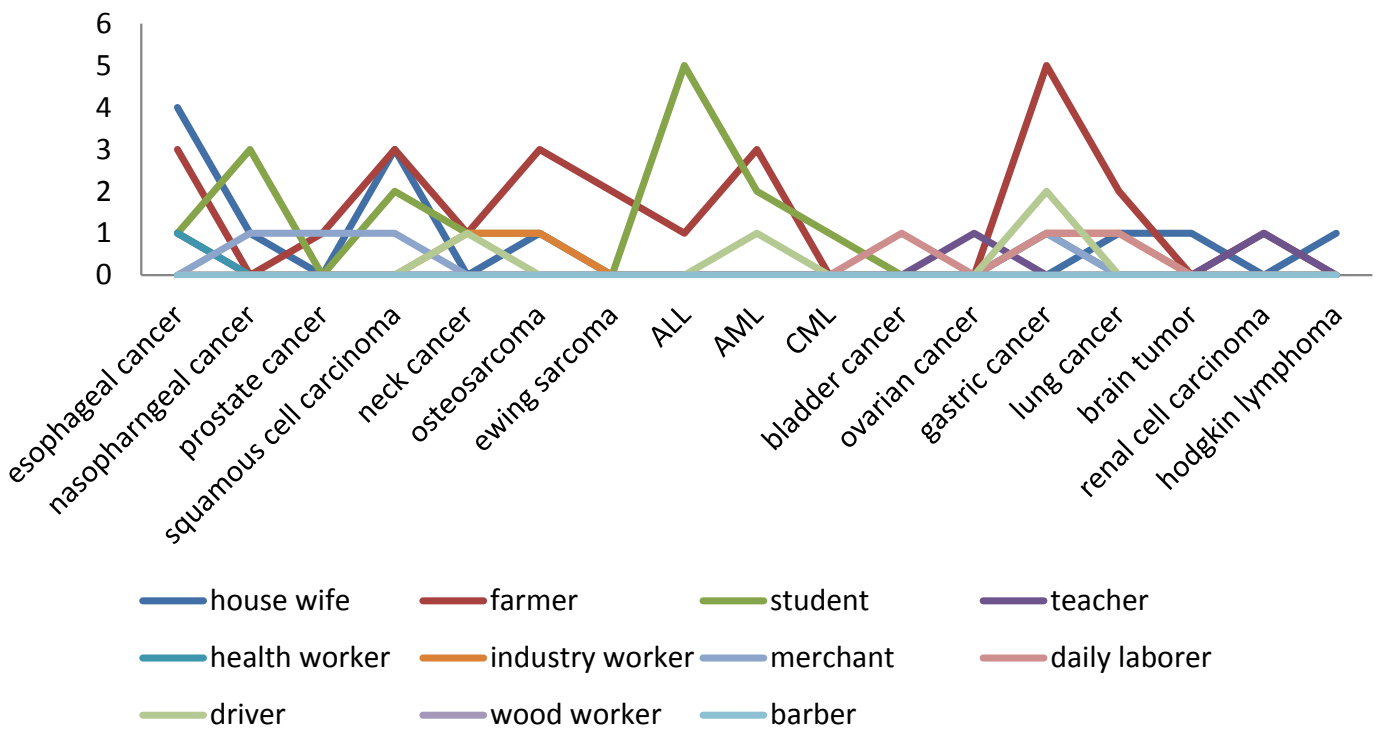

Figure 3: Distribution of cancer type by occupation among cancer patients at onclolgy unit of Tikur Anbessa Specilized Hospital, Addis Ababa, Ethiopia; 2016.

were often higher among young children. Studies also revealed that rates of white children were generally higher than those of black children, especially during the first 5 years of life $[34,35]$.

In most of the studies, a slight excess risk of prostate cancer incidence or mortality was observed among farmers. It is as yet unclear whether this excess risk is caused by particular occupational exposures or by risk factors in their personal lifestyle (e.g. dietary habits) [36].

Many studies also associated rectal cancer with several retail industries; prostate cancer with ministers, farmers, plumbers, and coal miners; malignant melanoma with school teachers; and invasive cervical cancer with women working in hotels and restaurants [37]. In our study, bladder CA was seen in daily laborers, osteosarcoma in industry workers, and gastric cancer in drivers.

\section{Other risk factors}

Smoking has been identified as the single most commonly associated risk factor in majority CA types for a number of studies done globally [38-40]. One study reported that cigarette smoking was more strongly associated with death from lung adenocarcinoma [41]. Smoking habit has large impact on causing cancer in males and respiratory cancers and gastrointestinal cancers were most common in males [42]. In our study three lung CA patients were a cigarette smoker for more than 10 years. Two from each AML, gastric and colorectal CA patients were also cigarette smoker (Tables 2 and 3). One study reported that, the dose response curve for intensity of smoking was steeper in women. The findings of this study provided additional evidence for a causal relationship between smoking and all histologic types of lung cancer [43].

Even if it was difficult to associate the number of cigarette use with respect to cancer type in our study, one AML and one lung cancer patient were using more than 15 pieces of cigarette per day. Two gastric CA and one Lung CA and one AML patients were also using 10-15 pieces of cigarette per day (Figure 4). One study also reported that Lifelong nonfilter smokers were at nearly twice the risk of lung cancer compared to lifelong filter smokers after controlling for duration of cigarette use and number smoked per day. Lung cancer risks for filter,

\begin{tabular}{|l|c|c|}
\hline Duration of smoking & Type of cancer & Number of patients \\
\hline \multirow{3}{*}{$5-10$ years } & breast caner & 1 \\
\cline { 2 - 3 } & nasopharngeal cancer & 1 \\
\cline { 2 - 3 } & AML & 2 \\
\hline \multirow{3}{*}{ > 10 years } & gastric cancer & 2 \\
\hline & colorectal cancer & 2 \\
\hline & esophageal cancer & 1 \\
\cline { 2 - 3 } & lung cancer & 3 \\
\hline
\end{tabular}

Table 2: A cross tabulation showing type of cancer versus cigarette smoking and duration of smoking. patients at onclolgy unit of Tikur Anbessa Specilized Hospital, Addis Ababa, Ethiopia; 2016.

\begin{tabular}{|c|c|c|c|c|}
\hline \multirow{2}{*}{$\begin{array}{l}\text { Most common } \\
\text { associated risk factors }\end{array}$} & \multicolumn{4}{|c|}{ Common cancer types } \\
\hline & $\begin{array}{l}\text { Colorectal } \\
\text { cancer }\end{array}$ & $\begin{array}{c}\text { Esophageal } \\
\text { cancer }\end{array}$ & $\begin{array}{l}\text { Gastric } \\
\text { cancer }\end{array}$ & $\begin{array}{l}\text { Lung } \\
\text { cancer }\end{array}$ \\
\hline Cigarette smoking & $2(1.4 \%)$ & $1(0.7 \%)$ & $2(1.4 \%)$ & $3(2.1 \%)$ \\
\hline Red raw meat & $12(8.5 \%)$ & $5(3.5 \%)$ & $9(6.3 \%)$ & $4(2.82 \%)$ \\
\hline Fabricated foods & $6(4.2 \%)$ & $2(1.4 \%)$ & $1(0.7 \%)$ & $1(0.7 \%)$ \\
\hline Hot foods and drinks & $2(1.4 \%)$ & $6(4.2 \%)$ & $1(0.7 \%)$ & $1(0.7 \%)$ \\
\hline Herbicides and pesticides & $2(1.4 \%)$ & $0(0 \%)$ & $4(2.82 \%)$ & $1(0.7 \%)$ \\
\hline
\end{tabular}

Table 3: Common cancer type with their associated risk factor, Onclolgy Unit of Tikur Anbessa Specilized Hospital, Addis Ababa, Ethiopia; 2016.

nonfilter and mixed smokers increased in proportion to intensity and duration of smoking and decreased with years since stopping smoking. The findings indicate that prevention activities should continue to emphasize smoking cessation, although switching to low-tar cigarettes may also yield some reductions in lung cancer risk [44].

An oral contraceptive agent has been revealed as a possible preventive treatment for breast CA [45]. In our study, among 20 patients who had breast CA, 65\% $(n=13)$ were used contraceptives at least once in their last 10 years period. Among uterine cancer patients $40 \%(n=8)$ were used either oral or injectable contraceptives. On the other hand, patients who had cervical CA were used either oral or injectable contraceptives $(30 \%, n=3)$ (Figure 5). In One case control study a multivariate relative risk estimate decreased prevalence of 




Figure 4: A cross tabulation showing type of cancer versus cigarette smoking and number of cigarette pieces used; at onclolgy unit of Tikur Anbessa Specilized Hospital, Addis Ababa, Ethiopia; 2016.

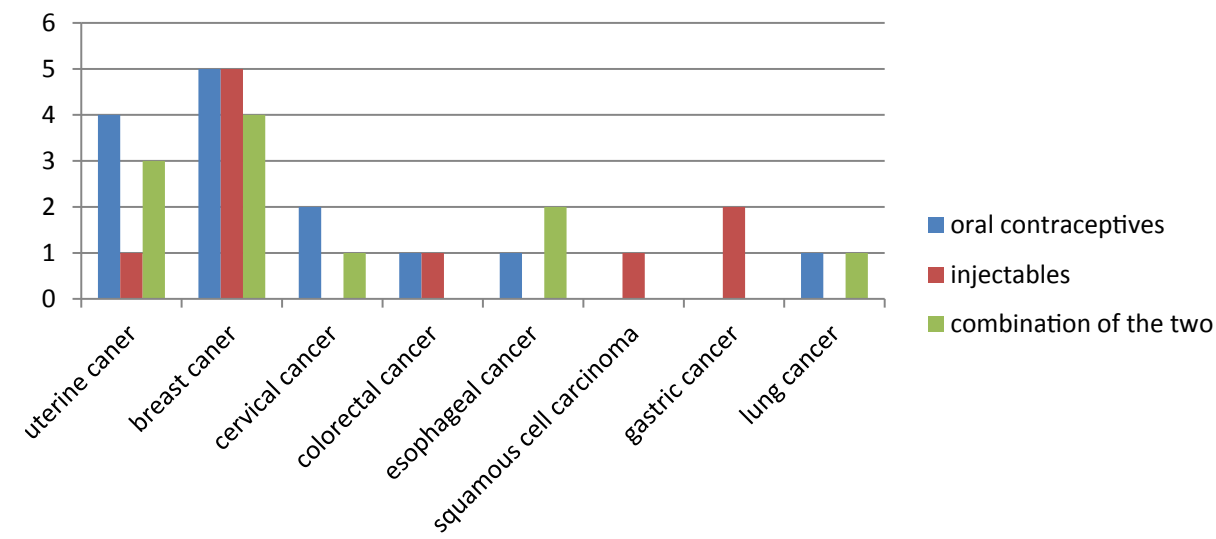

Figure 5: Type of cancer versus type of family planning methods used; at onclolgy unit of Tikur Anbessa Specilized hospital, Addis Ababa, Ethiopia; 2016.

invasive epithelial ovarian CA with the increasing duration of oral contraceptive use [46].

In our study prevalence of breast CA was not affected by the duration of contraceptive use rather it was stable across the duration of use. However, the prevalence of uterine cancer was slightly increased by duration of contraceptive use (Figure 6).

Many patients who were developed colorectal CA 12 (8.5\%) and gastric CA 9 (6.3\%) were reported that they were regularly eating uncooked red meat as their favorite meal. Also, $6(4.2 \%)$ patients who were developed colorectal CA were also eating factory processed meal including tomato, fish, juices etc. regularly (Table 3).

\section{Cancer management approaches in the study area}

Access to cancer treatment has been a challenge for third world countries patients. Considering the case of TASH oncology unit, until recently that was the only referral site for CA cases. Many patients die before getting the right treatment. Among the treatment modalities chemotherapy, radiation, surgery and immunotherapy have been mentioned and the choice is dependent on the specific CA treatment protocol. Surgery has been promising in early stage solid CA cases with adjuvant or neo-adjuvant radiation therapy. Therefore, the increasing the service of this approach may need priority so as to decrease mortality from CA.

In our study, many patients were receiving radiation therapy for cases such as uterine, breast, cervical and colorectal CA while chemotherapy were predominantly used in cases such as colorectal, squamous cell, osteosarcoma, ALL, AML and lung cancer. Many patients were received surgery for gastric and esophageal CA. Chemotherapy and surgery was considered in case of breaset and gastric CAs. Chemotherpy and radiation was done for Uterine, breast, colorecat, neck and lung CA. Combination of radiation, chemotherapy and surgery also done for cases such as breast and gastric CA (Figure 7).

Multinomial regressional analysis further revealed that there was a significant association between breast CA with age b/n 25-49 year (P. value 0.016 ), uterine and cervical CA with female gender (P. value 0.001); and eating of uncooked red raw meat with colorectal CA (P. value 0.011). Since, the most common type of cancers reported were cervical and uterine CA then its association with sex as well as age is expected to be associated with female gender. Some studies already reported that, the presence of an increased risk for colorectal cancer followed by consumption of cooked and processed red meat consistently for longtime [47]. However, the association of eating uncooked raw meat and 


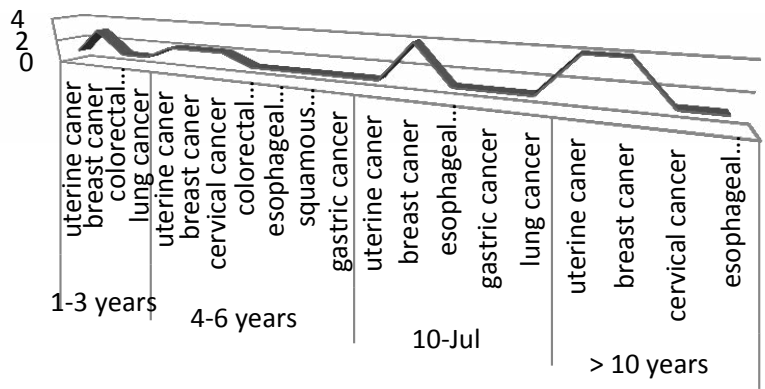

Number of Patients

Figure 6: A cross tabulation showing type of cancer versus family planning and duration of family planning use.

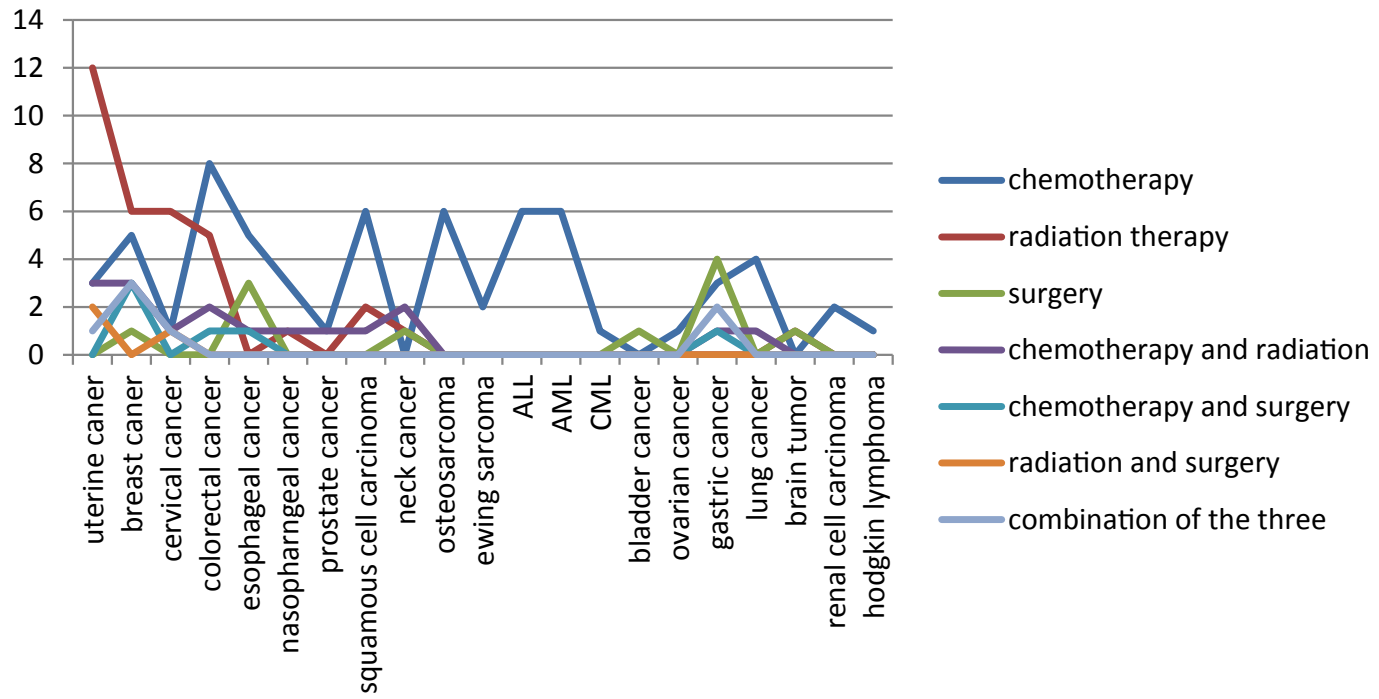

Figure 7: Distribution of cancer type by occupation among cancer patients at onclolgy unit of Tikur Anbessa Specilized Hospital, Addis Ababa, Ethiopia; 2016.

its association with colorectal CA may need additional study and close observation.

\section{Conclusions}

In our study uterine, breast, cervical, colorectal and gastric CA were more common in age group between 25-49 years while ALL was more common in 13-18 years of age, and Ewing sarcoma was most prevalent in age between 19 and 24 years. Breast CA was the most frequent type of CA followed by uterine CA. ALL was common in students, while gastric, lung, AML, osteosarcoma; and squamous cell CA were common in farmers. Many patients who were developed colorectal CA and gastric CA were reported that they were regularly eating uncooked red meat as their favorite meal. Our study revealed that there was a significant association between breast CA with age b/n 25-49 year ( $\mathrm{P}$. value 0.016 ), and eating of uncooked red raw meat with colorectal CA (P. value 0.011).

\section{Competing Interests}

The authors declare that they have no competing interests.

\section{Authors' Contributions}

MAW discovered the area, designed the study and revised the whole manuscript. DAL and FEA collected the data and wrote the draft including analysis; and $A B B$ reviewed the whole document. All authors read and approved the final manuscript.

\section{Acknowledgment}

We would also like to acknowledge Addis Ababa University, College of Health Sciences, School of Pharmacy for giving us this chance to conduct the study on this topic and also like to extend our gratitude to Tikur Anbessa Specialized Hospital, Oncology Unit staff as well as patients for their cooperation during data collection. Finally it is our pleasure to acknowledge all those who have directly and/ or indirectly provided us their supports.

\section{References}

1. Cordella M, Poiani A: Introduction (2014) In: Behavioural Oncology. Edn Springer pp 1-10.

2. Ytayew SA, Shibabaw ME, Vagrecha Y: Effectiveness of existential group therapy for treatment of psychological problem of cervical cancer patients. Innovare J Soc Sci 2015

3. Jemal A, Bray F, Center MM, Ferlay J, Ward E, et al. (2011) Global cancer statistics. CA: CA Cancer J Clin 61: 69-90.

4. Baker KS, DeFor TE, Burns LJ, Ramsay NK, Neglia JP, et al. (2003) New malignancies after blood or marrow stem-cell transplantation in children and adults: Incidence and risk factors. J Clin Oncol 21: 1352-1358.

5. Bendall SC, Nolan GP (2012) From single cells to deep phenotypes in cancer Nat Biotechnol 30: 639-647.

6. Joshi SK, Jadon G (2012) Introduction to neoplasm: Tumor classification-A reviewarticle. Int J Adv Res Pharm Biosci 1: 227-263. 
Citation: Woldu MA, Legese DA, Abamecha FE, Berha AB (2017) The Prevalence of Cancer and its Associated Risk Factors among Patients Visiting Oncology Unit, Tikur Anbessa Specialized Hospital, Addis Ababa-Ethiopia. J Cancer Sci Ther 9: 414-421. doi: 10.4172/1948-5956.1000452

7. McSweeney PA, Niederwieser D, Shizuru JA, Sandmaier BM, Molina AJ, et al. (2001) Hematopoietic cell transplantation in older patients with hematologic malignancies: Replacing high-dose cytotoxic therapy with graft-versus-tumo effects. Blood 97: 3390-3400.

8. Doll R, Peto R (1981) The causes of cancer: Quantitative estimates of avoidable risks of cancer in the United States today. J Natl Cancer Inst 66: 1192-1308.

9. Trichopoulos D, Li FP, Hunter DJ (1996) What causes cancer? Scientific American 275: 80-84

10. World Health Organization (2008) World malaria report. World Health Organization.

11. Parkin DM, Bray F, Ferlay J, Pisani $P(2001)$ Estimating the world cancer burden: Globocan 2000. Int J Cancer 94: 153-156.

12. Torre LA, Bray F, Siegel RL, Ferlay J, Lortet-Tieulent J, et al. (2015) Globa cancer statistics, 2012. CA: CA Cancer J Clin 65: 87-108.

13. Kasper DL, Fauci AS, Hauser SL, Longo DL, Jameson JL, et al. ( 2015) Harrisons principles of internal medicine cancer genetics. USA; McGraw-Hill.

14. Ilyas M, Straub J, Tomlinson I, Bodmer W (1999) Genetic pathways in colorecta and other cancers. Eur J Cancer 35:1986-2002.

15. Studer H, Derwahl M (1995) Mechanisms of nonneoplastic endocrine hyperplasia: A changing concept: A review focused on the thyroid gland. Endocr Rev 16: 411-426.

16. Berhane Y, Mariam DH, Kloos H (2006) Epidemiology and ecology of health and disease in Ethiopia: Shama books.

17. Levine AJ (1993) The tumor suppressor genes. Annu Rev Biochem 62: 623-651.

18. Levine AJ, Momand J (1990) Tumor suppressor genes: The p53 and retinoblastoma sensitivity genes and gene products. Biochimica et Biophysica Acta (BBA)-Reviews on Cancer 1032: 119-136.

19. Hanahan D, Weinberg RA (2011) Hallmarks of cancer: The next generation. Cell 144: 646-674.

20. Parkin DM (2001) Global cancer statistics in the year 2000. Lancet oncol 2: 533-543.

21. Organization WH (2010) World health statistics 2010: World Health Organization.

22. Bray F, Ren JS, Masuyer E, Ferlay J (2008) Global estimates of cancer prevalence for 27 sites in the adult population in 2008. Int J Cancer 132: 1133-1145.

23. Dalal S, Beunza JJ, Volmink J, Adebamowo C, Bajunirwe F, et al. (2011) Noncommunicable diseases in sub-Saharan Africa: What we know now. Int $J$ Epidemiol 40: 885-901.

24. Asaria P, Chisholm D, Mathers C, Ezzati M, Beaglehole R (2007) Chronic disease prevention: Health effects and financial costs of strategies to reduce salt intake and control tobacco use. The Lancet 370: 2044-2053.

25. Misganaw A, Mariam DH, Ali A, Araya T (2014) Epidemiology of major noncommunicable diseases in Ethiopia: a systematic review. Journal of health, population, and nutrition 32: 1.

26. Horton R, Abegunde Do, Mothers CD, Adam T, Ortegon M, et al. (2007) The burden and costs of chronic diseases in low-income and middle-income countries. Commentary. Lancet : 370.

27. Morhason-Bello IO, Odedina F, Rebbeck TR, Harford J, Dangou JM, et al (2013) Challenges and opportunities in cancer control in Africa: A perspective from the African organisation for research and training in cancer. Lancet Onco 14: e142-e151.
28. Stewart B, Wild CP (2014) World cancer report 2014. World 2015

29. DePinho RA (2000) The age of cancer. Nature 408: 248-254.

30. Jemal A, Center MM, DeSantis C, Ward EM (2010) Global patterns of cancer incidence and mortality rates and trends. Cancer Epidemiol Biomarkers Prev 19:1893-1907.

31. Parkin DM, Pisani P, Ferlay J (1999) Estimates of the worldwide incidence of 25 major cancers in 1990. Int J Cancer 80: 827-841.

32. Parkin DM, Bray F, Ferlay J, Pisani P (2005) Global cancer statistics, 2002. CA Cancer J Clin 55: 74-108.

33. Siegel R, Naishadham D, Jemal A (2013) Cancer statistics, 2013. CA Cancer J Clin 63: 11-30.

34. Wiemels J, Cazzaniga G, Daniotti M, Eden O, Addison G, et AL. (1999) Prenata origin of acute lymphoblastic leukaemia in children. Lancet 354: 1499-1503.

35. Gurney JG, Severson RK, Davis S, Robison LL (1995) Incidence of cance in children in the United States. Sex-, race-, and 1-year age-specific rates by histologic type. Cancer 75: 2186-2195.

36. Dubrow R, Wegman DH (1984) Cancer and occupation in Massachusetts: A death certificate study. Am J Ind Med 6: 207-230.

37. Williams RR, Stegens NL, Goldsmith JR (1977) Associations of cancer site and type with occupation and industry from the Third National Cancer Survey Interview. J Natl Cancer Inst 59: 1147-1185.

38. Venook AP, Papandreou C, Furuse J, de Guevara LL (2010) The incidence and epidemiology of hepatocellular carcinoma: A global and regional perspective. Oncologist 15: 5-13.

39. Blot WJ, McLaughlin JK, Winn DM, Austin DF, Greenberg RS, et al. (1988) Smoking and drinking in relation to oral and pharyngeal cancer. Cancer Res 48: 3282-3287.

40. Khuder SA (2001) Effect of cigarette smoking on major histological types of lung cancer: A meta-analysis. Lung cancer 31: 139-148.

41. Thun MJ, Lally CA, Calle EE, Heath JCW, Flannery JT (1997) Cigarette smoking and changes in the histopathology of lung cancer. JNCl: J Natl Cancer Inst 89: 1580-1586.

2. Shamsuzzaman M (2012) Identification of risk factors in the development various types of cancers and common chemo drugs use pattern in Bangladesh. East West University.

43. Thun MJ, Lally CA, Calle EE, Heath CW, Flannery JT, et al. (1997) Cigarette smoking and changes in the histopathology of lung cancer. J Natl Cancer Inst 89: $1580-1586$.

44. Lubin JH, Blot WJ, Berrino F, Flamant R, Gillis CR, et al. (1984) Patterns of lung cancer risk according to type of cigarette smoked. Int J Cancer 33: 569-576.

45. Narod SA, Risch H, Moslehi R, Dørum A, Neuhausen S, et al. (1998) Oral contraceptives and the risk of hereditary ovarian cancer. N Eng J Med 339: 424-428.

46. Rosenberg L, Palmer JR, Zauber AG, Warshauer ME, Lewis JL, et al. (1994) A case-control study of oral contraceptive use and invasive epithelial ovarian cancer. Am J Epidemiol 139: 654-661.

47. zur Hausen H (2012) Red meat consumption and cancer: reasons to suspect involvement of bovine infectious factors in colorectal cancer. Int J Cancer 130 2475-2483. 